\title{
Comparison of GPS-TEC measurements with IRI2012-TEC predictions in the Brazilian sector during the unusual solar minimum 2009
}

\author{
Alessandro José de Abreu ${ }^{1}$, Inácio Malmonge Martin ${ }^{1}$, Rodolfo de Jesus ${ }^{2}$, \\ Maurício José Alves Bolzan ${ }^{3}$, Kavutarapu Venkatesh ${ }^{4}$, Paulo Roberto Fagundes ${ }^{4}$, \\ Mauro Angelo Alves ${ }^{1}$, Maurício Gende ${ }^{5}$ and Sanjay Kumar ${ }^{6}$ \\ ${ }^{1}$ Instituto Tecnológico de Aeronáutica (ITA), Divisão de Ciências Fundamentais, São José dos Campos, SP, Brazil \\ ${ }^{2}$ Instituto Nacional de Pesquisas Espaciais (INPE), São José dos Campos, SP, Brazil \\ ${ }^{3}$ Departamento de Física, Universidade Federal de Goiás (UFG), Campus Jataí, Goiás, Brazil \\ ${ }^{4}$ Universidade do Vale do Paraíba (UNIVAP), Laboratório de Física e Astronomia, São José dos Campos, SP, Brazil \\ ${ }^{5}$ Facultad de Ciencias Astronómicas y Geofisicas, Universidad Nacional de La Plata (UNLP), La Plata, Argentina \\ ${ }^{6}$ Banaras Hindu University, Varanasi-221005, Índia
}

Article history

Received November 3, 2016; accepted March 8, 2017.

Subject classification:

GPS, IRI model, TEC, ionosphere, F-region.

\begin{abstract}
The total electron content (TEC) derived from two Global Positioning System (GPS) receivers localized at Palmas (PAL, $10.2^{\circ} \mathrm{S}, 48.2^{\circ} \mathrm{W}$, dip latitude $5.5^{\circ} \mathrm{S}$ ), near equatorial region, and São José dos Campos (SJC, $23.2^{\circ} \mathrm{S}, 45.9^{\circ} \mathrm{W}$, dip latitude $\left.17.6^{\circ} \mathrm{S}\right)$, under the southern crest of the equatorial ionization anomaly (EIA), in the Brazilian sector are used in this paper. TEC from the latest available IRI-2012 model at the same locations is also used. A comparative study between GPS-TEC and the IRI-2012 model is analyzed during the deep low solar activity period of 2009 in the unusual solar cycle 23. The measurements and the modeled data show that the IRI-TEC model gives the better estimates of the GPS-TEC during the nighttime from January to December months at PAL and SJC. The IRI-TEC model shows larger differences from the GPS-TEC in the afternoon hours, mainly at SJC. These discrepancies observed at SJC in the afternoon hours for all months are possibly due to the dynamics of EIA in consequence of the equatorial fountain effect. At PAL and SJC, oscillations of GPS-TEC with periods around 16 days in April and periods around 27-32 days between September and December possibly are noticed which could be related to a modulation of the semidiurnal tide and Sun's rotation, respectively. Also, oscillations with periods around 2-4 and 5-10 days from January to December are observed at PAL and SJC, possibly associated with the propagation of planetary waves.
\end{abstract}

\section{Introduction}

The ionosphere is a dispersive medium, which affects the propagation of electromagnetic waves. The new communications technologies, ranging from ra- dio broadcasting to the most complex satellite navigation systems operate with electromagnetic waves in the radio frequency range. The equatorial and low latitude regions of the ionosphere have unique characteristics due to the horizontal geomagnetic field lines and due to the absorption of larger fraction of incident solar energy [Abdu, 2000, 2005]. The Earth's ionosphere is affected by complex electrodynamics processes from the dynamic interactions between the neutral atmosphere and the ionospheric plasma. Such processes are controlled by the neutral winds of the upper atmosphere which interact with the conductive and magnetic regions of the ionosphere and produced by dynamo effect, electric fields in the ionospheric Eand F-regions. The dynamo electric fields are generated in the equatorial E-region by thermospheric winds caused by horizontal gradients of pressure existing in the atmosphere due to the variation of the solar radiation absorption, which is conducted along the geomagnetic field lines at high altitudes of the F-region due to high parallel conductivity. During the daytime, the dynamo electric field $\mathbf{E}$ is directed to the east and the geomagnetic field $\mathbf{B}$ is directed to the north resulting in an electromagnetic (E x B) drift upward, bringing the plasma to higher altitudes in the equatorial region. The elevated plasma diffuses down along the geomagnetic field lines due to the force of gravity $\mathbf{g}$ and pressure gradients $\nabla_{p}$, which is known as the equatorial 
fountain effect [Kelley et al., 2006]. As a result, two ionization crests are formed on either sides of the geomagnetic equator at around $\pm 20^{\circ}$ magnetic latitudes with the anomaly trough centered at the geomagnetic equator. This phenomenon is known as equatorial ionization anomaly (EIA) or Appleton anomaly [Abdu, 2005].

The total electron content (TEC) is an important parameter which is widely used to study the ionospheric characteristics. The TEC shows diurnal, monthly, seasonal and spatial variations and is influenced by several factors such as solar cycle and geomagnetic activity. The TEC variations under various solar and geophysical conditions have been studied by numerous investigators using different techniques [e.g., Mannucci et al., 1998; Brunini et al., 2003; Wu et al., 2008; Bolaji et al., 2012; de Abreu et al., 2014a, 2014b]. With the advent of the Global Positioning System (GPS) satellites, the quantum of TEC measurements all over the globe has been increased numerously and giving an opportunity for the ionospheric community to investigate the ionospheric characteristics more in detail.

Empirical models play an important role in predicting the variations of different ionospheric parameters. The International Reference Ionospheric (IRI) model is most widely used by the scientific community to compute the variations of electron density and other parameters of the ionosphere. The IRI model was developed by the Committee on Space Research (COSPAR) and the International Union of Radio Science (URSI) with the first version in 1978 [Rawer et al., 1978]. It has been continuously improved and updated with new data and modeling techniques over the years [Bilitza, 1986, 1990, 2001; Bilitza and Reinisch, 2008] until the latest the IRI2012 model [Bilitza et al., 2014] with significant improvements. In this latest version several changes have been made to estimate the electron density, electron temperature as well as the ion composition. A new model developed by Truhlik et al. [2012] to describe the solar activity variations of electron temperature has been included in the latest IRI-2012 version. Altadill et al. [2009] proposed a new model for the estimation of bottom side electron density profiles and reported improvements in their method. This method proposed by Altadill et al. [2009] has been employed in the latest IRI-2012 model as "ABT-2009" which is a default option for bottom side profile estimation. The studies of Bhuyan and Rashmi [2007], Akala et al. [2013], Maltseva et al. [2013], and references therein, reported a comparative analysis between the GPS-TEC (TEC observed) and the IRITEC (TEC modeled) at different latitudes and longitudes. Thus, the studies have shown a certain agreement in relation to the IRI-TEC model and GPS-TEC in highand mid-latitudes, whereas, it does not show agreement at equatorial and low latitudes [Venkatesh et al., 2011].

The objective of the present study is to carry out a comparative study of GPS-TEC measurements with the IRI-2012 model prediction at Palmas (PAL), near equatorial region, and São José dos Campos (SJC), under the southern crest of the EIA, in the Brazilian sector. Figure 1 provides the locations of the GPS sites used in the present study. It is of the intention to study the IRI-2012 model performance in estimating the diurnal, seasonal and latitudinal characteristics of ionospheric electron

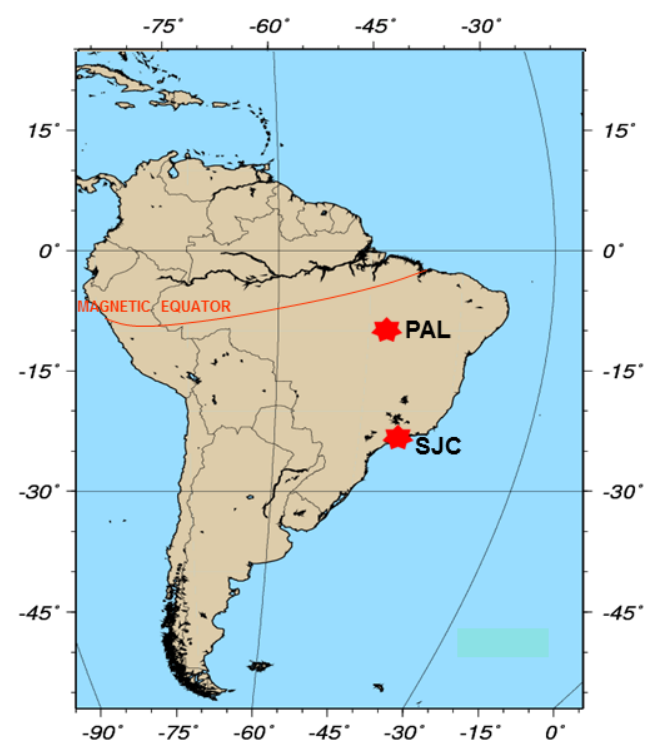

Figure 1. Map marked with red asterisks indicating the locations of the GPS stations. The geographic and magnetic equators are also shown.

density during the extreme low solar activity period of 2009. Further, the wavelet analysis has been used to compare the periodic characteristics of TEC from experimental and modeled outputs. This study focuses on the deep low solar activity period 2009 of the unusual solar cycle 23 , which was very weak as compared to several previous years. In order to understand the causes for the discrepancies, the GPS-TEC measurements and the IRI-2012 prediction has been analyzed.

\section{Data and Methodology}

In the present study, the GPS-TEC measurements over a near equatorial station Palmas $\left(10.2^{\circ} \mathrm{S}, 48.2^{\circ} \mathrm{W}\right.$, dip latitude $5.5^{\circ} \mathrm{S}$; hereafter referred to as PAL) and an anomaly crest location, São José dos Campos $\left(23.2^{\circ} \mathrm{S}\right.$, $45.9^{\circ} \mathrm{W}$, dip latitude $17.6^{\circ} \mathrm{S}$; hereafter referred to as SJC) during the extreme low solar activity year of 2009 are considered. The GPS data over two stations were retrieved in standard Receiver Independent Exchange 
(RINEX) format. The PAL station belongs to the "Rede Brasileira de Monitoramento Contínuo (RBMC)" and is operated by the "Instituto Brasileiro de Geografia e Estatística (IBGE)". The SJC station belongs to the "Universidade do Vale do Paraíba (UNIVAP)".

The dual frequency measurements of GPS at L1 $(1575.42 \mathrm{MHz})$ and $\mathrm{L} 2(1227.60 \mathrm{MHz})$ are analyzed to derive the Slant TEC (STEC) values using the differential delay technique [Oron et al., 2013 and Seemala and Valladares, 2011]. Thus, derived STEC values along the satellite ray path are converted into Vertical TEC (VTEC) using a thin shell approximation and considering the ionospheric height as $350 \mathrm{~km}$ using the following relation.

$$
\text { VTEC }=\left[\text { TEC }_{R}-\left(b_{R}+b_{S}\right)\right] / S(E)
$$

where $S(E)$ is the single layer mapping function of the ionosphere defined by

$$
\mathrm{S}(\mathrm{E})=\sec \left\{\sin -1\left[\left(\mathrm{R}_{\mathrm{e}} \cos \varepsilon\right) /\left(\mathrm{R}_{\mathrm{e}}+\mathrm{h}\right)\right]\right\}
$$

where $\mathrm{R}_{\mathrm{e}}$ and $\mathrm{h}$ are the Earth's radius $(\sim 6378.1 \mathrm{~km})$ and ionospheric height in $350 \mathrm{~km}$, respectively, and $\varepsilon$ is the elevation angle in radians.

The latest IRI-2012 model derived TEC is obtained using the web based version available at http:// omniweb.gsfc.nasa.gov/vitmo/iri2012_vitmo.html. In the IRI model, initially it estimates the F-region peak parameters using URSI/CCIR coefficients. Then it uses different formulations to derive the bottom-side and top-side vertical electron density profiles. Thus derived vertical electron density profile is integrated with respect to altitude to compute the Total Electron Content value. In the present study, the 'URSI' option for 'F-peak model' is considered in the IRI-2012 model. Further, as described above, the newly added and the default 'ABT-2009' option is considered for bottom-side profile estimation and for the top-side profile, the default NeQuick option has been used. The IRI-2012 modeled TEC is obtained for PAL and SJC stations for comparison with the GPS observations.

The difference between TEC values derived from GPS data and values obtained from IRI-2012 model was calculated by:

$$
\mathrm{dTEC}=(\text { IRI2012-TEC }- \text { GPS-TEC })
$$

Further, we used the Continuous Wavelet Transform (CWT) to identify the periodicities in GPS measured and IRI modeled TEC variations. The CWT is a powerful mathematical tool for non-stationary signals and gives us information about the behavior of intermittency and periodic phenomena presents on these signals [Torrence and Compo, 1998]. Basically, the CWT is given by:

$$
W x(s, b)=\frac{1}{s} \int x(t) \psi^{*}\left[\frac{t-b}{s}\right] d t
$$

where $x(t)$ is the time-frequency domain, $s$ and $b$ are the scale and time, respectively, and $\psi^{*}$ is the conjugate complex of the mother wavelet $\psi$.

Therefore, it is very important to correlate two time series in order to verify if these time series have similar frequencies. Thus, the methodology is to apply the coherence phase between two time series using the following equation [Carey et al., 2013]:

$$
R_{n}^{2}(s)=\frac{\left|S\left(s^{-1} W_{n}(s)\right)\right|^{2}}{S\left(s^{-1} W_{n}^{X}(s)\right) \times S\left(s^{-1} W_{n}^{Y}(s)\right.}
$$

where $W_{n}^{X}$ and $W_{n}^{Y}$ are the WT applied on the $x$ and $y$ time series, respectively. The $S$ is a smoothing operator both in the scale and time domain.

The $\mathrm{F}_{10.7} \mathrm{~cm}$ solar flux index and sunspot numbers data has been obtained from the National Aeronautics and Space Administration (NASA) by the website http://omniweb.gsfc.nasa.gov/form/dx1.html. These indices are used to estimate the solar activity level.

\section{Results and Discussions}

Figure 2 presents the $\mathrm{F}_{10.7}$ index, $\left(\mathrm{Wm}^{-2} \mathrm{~Hz}^{-1}\right)$, and sunspot number variations between 1995 and 2016 . The vertical red lines represent the year 2009 considered in this study. The solar cycle 23 started in 1996 reaching its peak in 2001 and then declining until 2009, thus starting the solar cycle 24 . The $\mathrm{F}_{10.7}$ and sunspot numbers during the years 2008-2009 were very low. During 2009, the $\mathrm{F}_{10.7}$ and sunspot numbers vary from 65.8 to 84.2 and from 6 to 46 , respectively. This minimum of solar cycle 23 has been considered unusual, being compared to a climatic period called the "Little Ice Age or Maunder Minimum" from about 1645 to 1710 and the "Dalton Minimum" from 1797 to 1825 , with very few sunspots were seen on the Sun [Hady, 2013]. This deep low solar activity period 2009 is studied by comparing TEC from ground based GPS measurements with the IRI-2012 model prediction.

\subsection{Comparison of the diurnal and seasonal variations} of TEC from GPS and IRI-2012

Figure 3 presents the diurnal variations of monthly mean GPS-TEC (black curves) and the IRI-TEC 


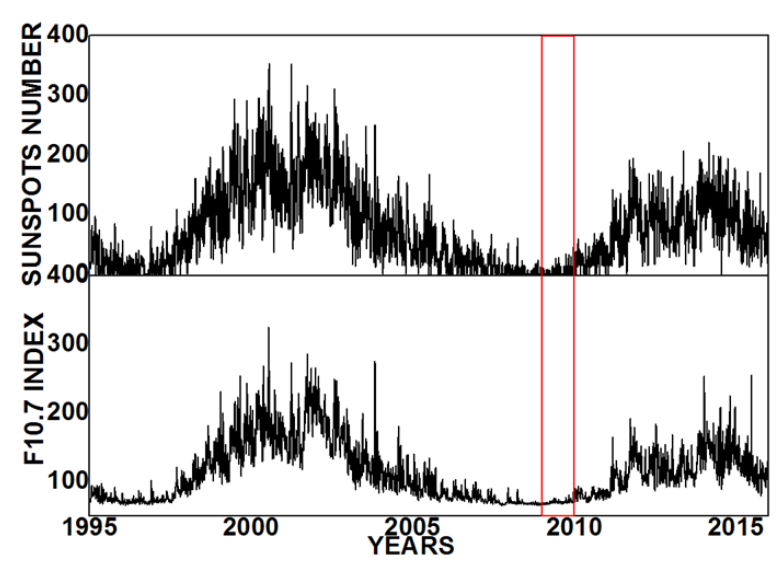

Figure 2. The F10.7 cm solar flux index and sunspots number variations through 1995-2016. The period of 2009 marked by vertical red lines was analyzed in this study.

model (green curves) at PAL station from January to December 2009. Figure 4 presents similar variations for SJC station. It is clearly seen from all these plots that the diurnal variations of GPS-TEC shows a minimum around 07:00-08:00 UT (04:00-05:00 LT) and a maximum in the afternoon hours with a peak around 16:00-18:00 UT (13:00-15:00 LT). The GPS-TEC shows higher values during spring (September, October, and November), summer (December, January, and February), and autumn (March, April, and May) months as compared to those during winter (June, July, and August) months at PAL and SJC. The GPS-TEC during nighttime remained with stable values from January to December months at PAL and SJC. The diurnal variations of TEC derived from the IRI-2012 model represent the mentioned features above, but overestimating (underestimating) the GPS-TEC in the afternoon hours (early morning hours) in the four seasons at PAL. On the other hand, the IRI-TEC model shows significant differences as compared to GPS-TEC at SJC. During January, February, October, and November, the IRI-TEC model underestimates the GPS-TEC in almost of the times, however, with larger differences in the afternoon hours as compared to those in the morning hours (until 08:00 UT - 05:00 LT). In other months, from March to September, the IRI-TEC model overestimates the GPSTEC in the afternoon hours and underestimates in the early morning hours with almost similar values. The exception occurs in March, where, the IRI model shows larger difference in the morning hours. It is important to note that the IRI-2012 model has a good agreement with the GPS-TEC during nighttime hours for four seasons at PAL and SJC. The IRI-2012 model shows larger differences from the GPS-TEC in the afternoon hours, which is larger and significant at SJC.
Figure 5 presents the contour diagram of the GPS-TEC and the IRI-TEC model as a function of month and universal time (UT) from January to December 2009 at PAL (top) and SJC (bottom) stations. The maximum day-time values of TEC from GPS and the IRI model are clearly observed from March to May and from September to November months at PAL. The IRI-TEC model shows maximum values around 16:00-18:00 UT (13:00-15:00 LT) at PAL and is higher as compared to GPS-TEC in all months. However, the

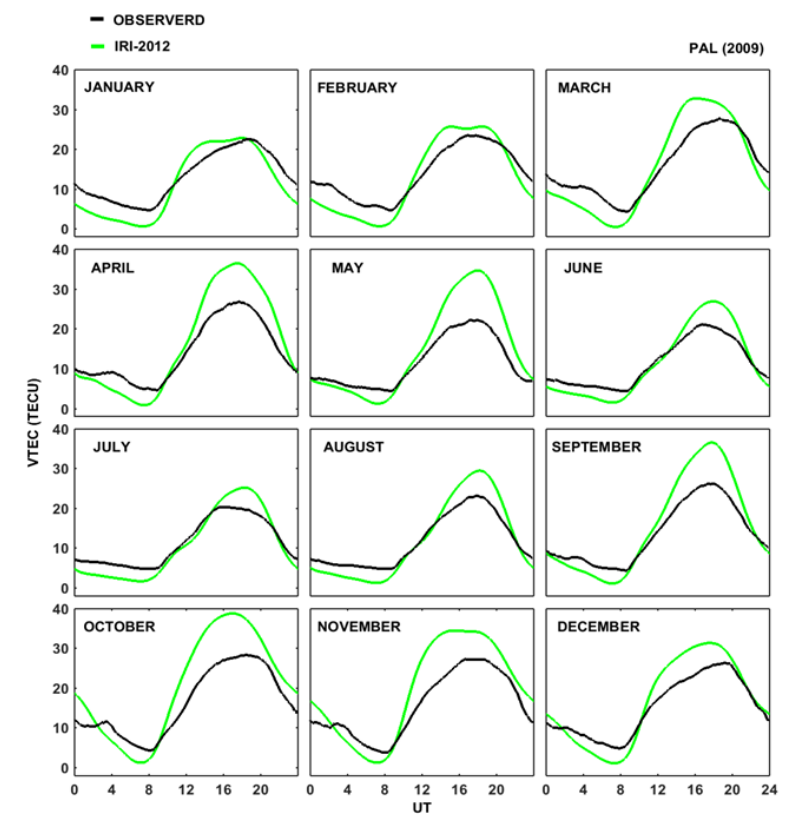

Figure 3. Comparison of monthly mean diurnal variations of GPS-TEC (black curves) and IRI2012-TEC (green curves) at PAL from January to December 2009.

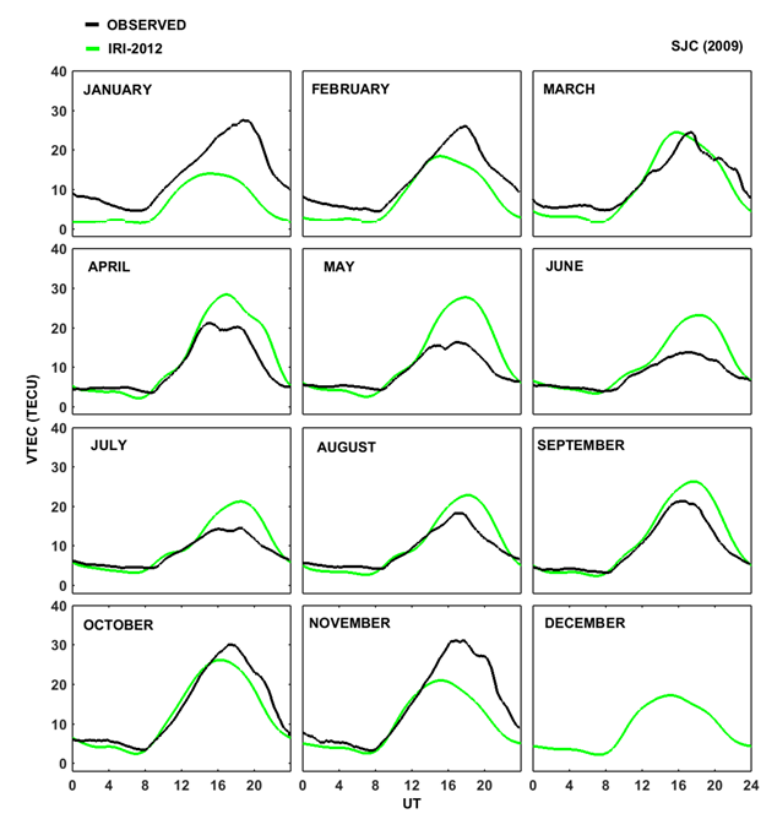

Figure 4. The same as in Figure 3 but for SJC station. 


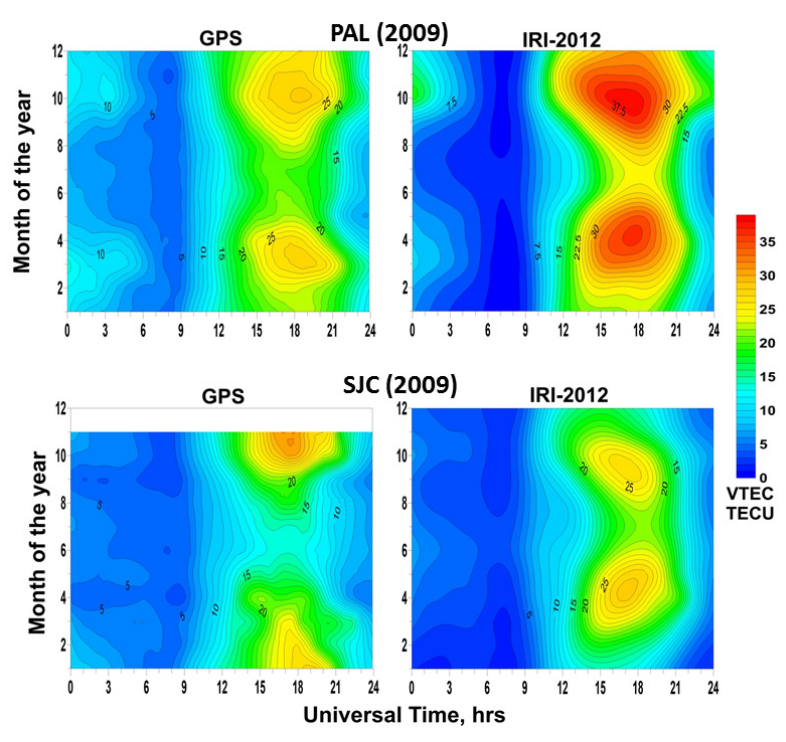

Figure 5. Contour diagram of the GPS-TEC and IRI2012-TEC as a function of month and mean diurnal variation from January to December 2009 at PAL (top) and SJC (bottom).

IRI-TEC model shows minimum values during 07:0008:00 UT (04:00-05:00 LT) and is lower as compared to GPS-TEC in all months. It is worth noting that the IRITEC model overestimates the GPS-TEC in the afternoon hours and underestimates in early morning hours in all four different seasons at PAL. At SJC, the IRI-TEC model underestimates the GPS-TEC from January to November in the early morning hours. During January, February, October, and November months, the IRITEC model underestimates the GPS-TEC in almost all hours while the model overestimates the GPS TEC during the remaining months.

\subsection{Variations of ATEC (difference between TEC} from GPS and IRI-2012)

Figure 6 presents the monthly mean diurnal variations of dTEC from January to December 2009 at PAL station. Figure 7 presents similar variations for SJC station. These figures present the exact difference in values between IRI-TEC model derived TEC and GPS-TEC in all months of 2009 at PAL and SJC. The dTEC positive (negative) values indicate that the IRITEC model overestimates (underestimates) the GPSTEC. At PAL, the dTEC crosses the 0 TECU level in certain times between 09:00 and 22:00 UT (06:00 and 19:00 LT) from January to September. From October to December the dTEC is positive between 09:00 and 02:00 UT (06:00-23:00 LT). However, before and after the record of 0 TECU, the dTEC recorded large positive and negative differences. From 00:00 to 10:00 UT (21:00 to 07:00 LT), the dTEC is negative with a maximum value of -6 TECU around 02:15 UT (23:15 LT) and 05:30 UT (02:30 LT) in February and March, respectively. Further, the dTEC is negative, but with a minimum value of -2 TECU around 00:00-02:00 UT (21:00-23:00 LT) in April, 00:00-04:00 UT (21:0001:00 LT) in May, 09:00-13:00 UT (06:00-10:00 LT) in June, and 00:00-01:00 UT (21:00-22:00 LT) in September. In contrast, it is possible to observe the positive dTEC in a range of time longer than the negative dTEC. The dTEC is positive with a minimum value of 2 TECU in late December and a maximum value of 12 TECU around 17:00-18:00 UT (14:00-15:00 LT) in May, October, and November. Therefore, during the daytime, the IRI-TEC model overestimates the GPS-TEC on a larger timescale at PAL.

At SJC, the dTEC shows larger discrepancy as compared to PAL (see Figure 7). The dTEC crosses 0 TECU level in certain times along the day. The dTEC is negative in all times of the day in January and February, with a maximum negative value of -17 TECU around 19:30 UT (16:30 LT) and a minimum negative value of -0.5 TECU around 14:00 UT (11:00 LT), respectively. In March, the dTEC is negative up to noon time and after that, it reaches a maximum positive value of 6 TECU around 14:30 UT (11:30 LT) and a maximum negative value of -6 TECU around 22:15 UT (19:15 LT). From April to September, the dTEC is negative around 00:00-08:00 UT (21:0005:00 LT), except June, during which it is positive around 00:00-01:00 UT (21:00-22:00 LT). Also during april to September, the dTEC shows a minimum negative value of -1 TECU around 07:50 UT (04:50 LT) in September and a maximum negative value of -2.5 TECU around 05:30 UT (02:30 LT) in May. During, May the maximum positive dTEC value of 12 TECU is noticed around 19:00 UT (16:00 LT). During October and November the ATEC shows similar kind of diurnal behaviour with the maximum negative values around 21:00 UT. The dTEC shows a maximum negative value of about -7 TECU during October while it nearly -14 TECU during November. The positive dTEC did not exceed 2 TECU in these two months. These observations reveal that the dTEC shows significant differences between PAL and SJC, especially in January, February, October, and November months.

It is of the significant importance to study the mechanisms responsible for the differences between GPS and IRI modeled TEC variations observed above. The electron density distribution in the ionospheric F-region in the equatorial and low latitude regions is 

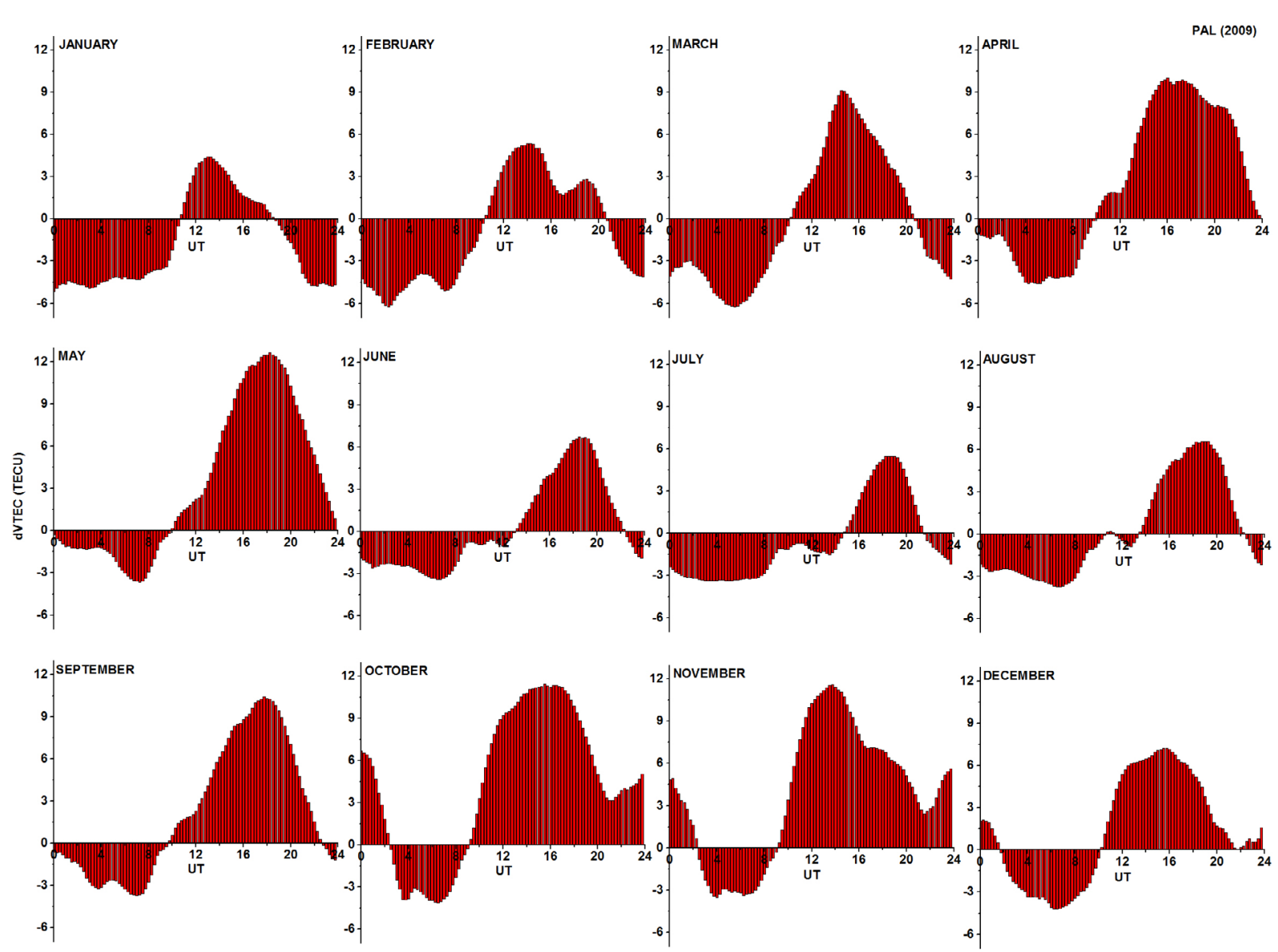

Figure 6. Monthly mean diurnal variations of dTEC at PAL from January to December 2009.

governed by different physical process, such as neutral winds, Equatorial Electrojet (EEJ), E x B drifts, and horizontal diffusion of ionization along the geomagnetic field lines. However, there are two major sources of plasma; one is the ionization due to the solar radiation and the other is the phenomena of the EIA. Tsai et al. [2001] analyzed the seasonal variations of the GPSTEC in the Asian sector of equatorial anomaly regions and they showed that both crests are fully developed around midday in winter, post-noon in equinoxes and late afternoon in summer. The two crests move significantly equatorward in winter but slightly poleward in summer and autumn, and these results were explained by neutral winds. de Jesus et al. [2011] analyzed different seasonal variations of ionospheric parameters, foF2 and hpF2 at PAL and SJC during medium solar activity periods. They showed that post sunset values of hpF2 observed at PAL presented an intense vertical drift during all the seasons. As it is well-known, there are a wide discrepancy between TEC measurements and the IRI model predictions at equatorial and low latitude regions [Bertoni et al., 2006]. The IRI-model is able to estimate well the GPS-TEC at high- and mid-la- titudes, but overestimates or underestimates at low latitudes, which was previously reported by authors [Venkatesh et al., 2011; Kumar et al., 2015a]. Venkatesh et al. [2011] compared GPS-TEC with the IRI-2007 model at Trivandrum (near equatorial region) and Waltair (low latitude), Indian stations. They found that the IRI-2007 model underestimated the GPS-TEC during the day and overestimated it during the night at both stations. Chakraborty et al. [2014] compared the GPSTEC with the IRI-2012 model over four stations from equatorial to mid-latitudes and they showed that the IRI-2012 model overestimated the GPS-TEC during the day time particularly in low latitude regions. They further concluded that the discrepancy appears to be higher in low latitude regions than mid-latitude during all seasons.

Our results show that during 2009 (the year of low solar activity) low values of GPS-TEC were observed. The observations also show significant discrepancies between GPS-TEC and the IRI-TEC model at equatorial region (PAL) and EIA region (SJC) in Brazilian sector. The IRI-TEC model shows better performance from nighttime to early morning hours 


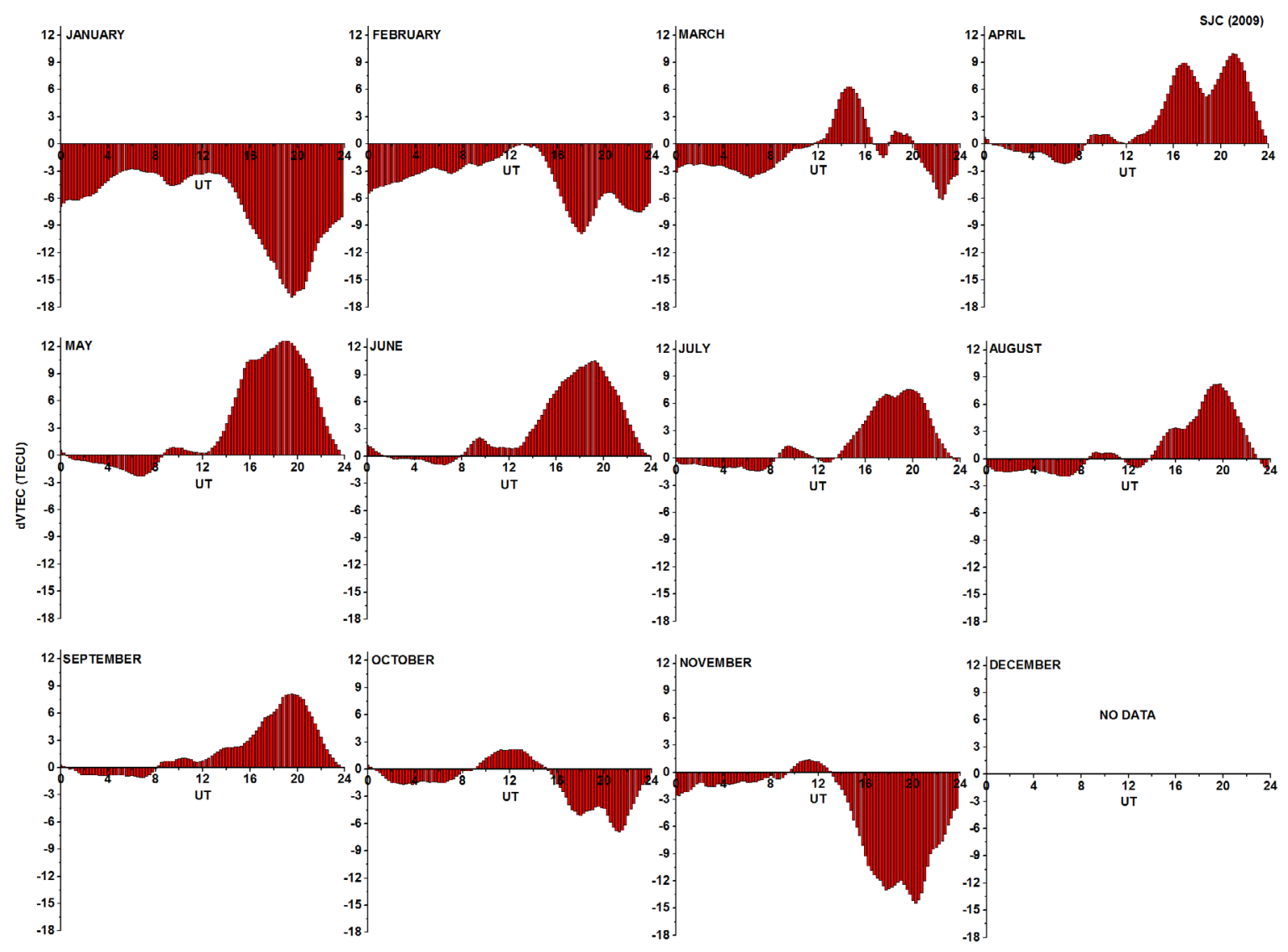

Figure 7. The same as in Figure 6 but for SJC station.

than that in the afternoon hours at both the regions. This result is important because it was expected major discrepancies at nighttime due to the fact the IRI-TEC model does not include the effects from the plasmasphere. In general, the GPS-TEC computes the TEC from ground all the way up to the plasmasphere, but the IRI-TEC model includes the ionosphere to the maximum altitude of only 2000 km [Kumar, 2016; Kenpankho et al., 2011]. However, the larger discrepancies observed at SJC station in the afternoon hours for all months are possibly due to dynamics of EIA region in consequence of the equatorial fountain effect, which the IRI model fails to predict correctly. The main driver of fountain effect is the $\mathbf{E} \times \mathbf{B}$ drifts over the equator controlled by the strength of the EEJ, leading to the electron density variability in the equatorial and low latitudes. These results agree with the results shown by Venkatesh et al. [2014a, 2014b] and Kumar et al. [2015a]. During the winter season, it is observed from the GPS-TEC that the EIA is weak keeping most of the ionization over the equator. Kumar et al. [2015b] analyzed the performance of the IRI2012-TEC predi- ctions in comparison with the GPS-TEC during the ascending phase of solar activity from 2009 to 2013 in different sectors (Singapore, Thailand, China, and Russia) from low to mid-latitudes. They showed that the IRI-model changes significantly as compared to GPS-TEC at EIA region during the solar minimum year 2009 and the changes decreases with the period of high solar activity year.

3.3. Comparison of the periodicities in the TEC variations from GPS and IRI-2012

In order to make comparison of the periodic characteristics of GPS-TEC and IRI-TEC model, the wavelet analysis has been carried out. Figure 8 and 9 present the wavelet analysis distribution of daily mean of GPS-TEC and IRI-TEC model, respectively, for 2009 at PAL and SJC stations. The white bands corresponds to the cone of influence obtained using the method proposed by Torrence and Compo [1998], where any oscillation under this cone does not have any statistical significance. The oscillations presented have different characteristics near equatorial (PAL) and low latitude (SJC) regions between GPS-TEC and IRI-TEC model. 


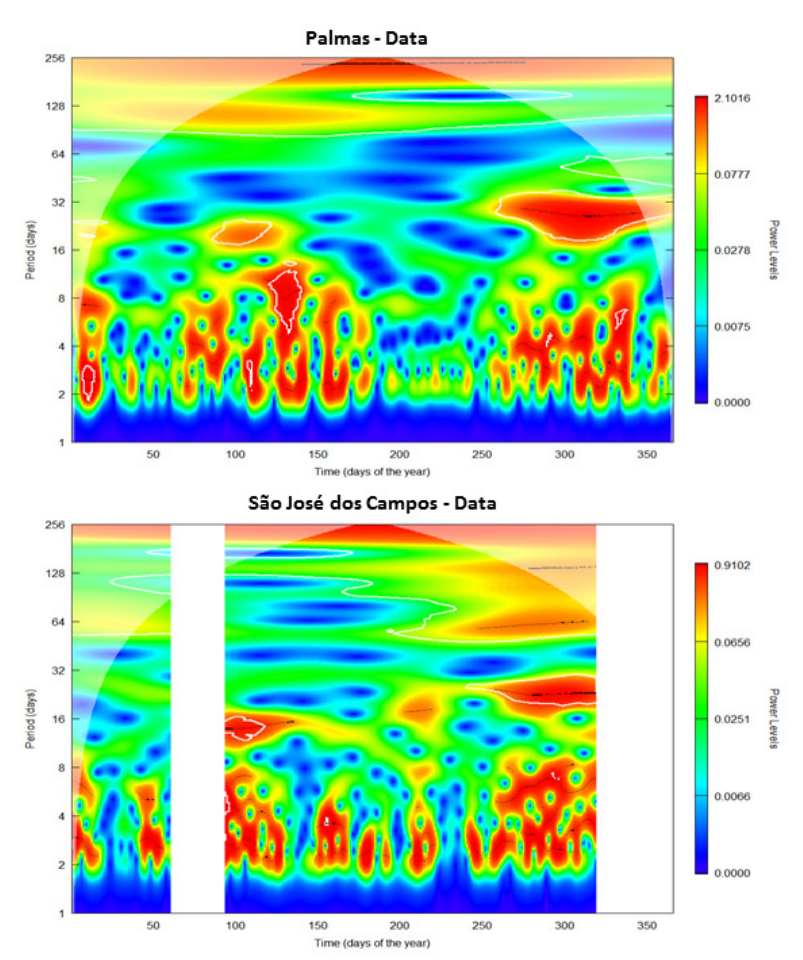

Figure 8. Continuous wavelet transform (CWT) power spectra analysis distribution of 2009 daily average GPS-TEC at PAL (top) and SJC (bottom). The vertical axis represents the daily period and the horizontal axis represents the day of the year.

Figure 8 presents the oscillations of GPS-TEC with periods around 16 days observed in April (days 90-120) and periods around 27-32 days observed between September and December (days 270-350) at PAL. Whereas in SJC, the same oscillations were observed in April and between September and November (data for December was not available). This possibly indicates that the near equatorial and low latitude regions in these periods are coupled. However, the periods around 16 days can be related to a modulation of the semidiurnal tide in the mesosphere to lower thermosphere region [Pancheva et al., 2002] and the periods around 27-32 days due to Sun's rotation time [Kutiev et al., 2012].

The oscillations with periods around 2-4 and 5-10 days have seasonal patterns near equatorial (PAL) and low latitude (SJC) regions from January to December (days 1-365) (Figure 8). The oscillations are more dominant during spring, summer, and autumn months and less dominant during winter months. This fact proves that the EIA is weaker during winter months. These oscillations may be associated with other mechanisms responsible for the ionospheric variability as the propagation of planetary waves in ionospheric altitudes. Jonah et al. [2015] using GPS-TEC data at equatorial and low latitude regions in the South American sector for 2001 and 2009, observed oscillations with periods around 1-5 and 8-10 days. They suggest that there are contributions of tides and planetary waves from the lower atmosphere in the TEC variability (also observed by Takahashi et al., 2005 and de Abreu et al., 2014c]. This scenario shows that the year 2009 has the presence of planetary waves, which can modulate the thermospheric winds and thereby modulate the $\mathbf{E} \times \mathbf{B}$ drift, i.e., EIA phenomena. It is interesting to observe that, during January and February at PAL and SJC, the oscillations also were less dominant, however, the opposite was expected. In this period, a major sudden stratospheric warming (SSW) event was occurred [Goncharenko et al., 2010]. Several observational and modeling studies during this SSW event have shown that it produce changes on the thermospheric winds influencing the ionospheric variability. Further details about SSW are beyond the scope of this paper, but can be found in Goncharenko et al. [2013], Fagundes et al. [2015], and references therein. This possibly explains the lack of pattern observed between January and February at PAL and SJC. In contrast, the wavelet analysis results had shown in Figure 9 a complete different scenario from that observed in Figure 8. The TEC-model shows the absence of oscillations with lower periods between 2 and 32 days. However, we can observe oscillations with periods around 128 days between April and September (days 90 to 270) at PAL and SJC. This shows a total discrepancy between the GPS-TEC and the IRI-TEC model for this period analyzed. The analyses were performed according to the red color of the power spectrum, which characterizes the highest energy level.

In order to study the agreement between GPS observed and IRI modeled data, we also applied the wavelet coherence between the daily average variations of GPS-TEC and the IRI-TEC modeled TEC for 2009 at PAL (top) and SJC (bottom) stations, which is presented in the Figure 10. The arrows indicate the phase difference between both time series where right arrows indicate series are in phase, left arrows indicate series are out of phase (1800), and vertical arrows indicate the second time series lags the first by 90o. According to Carey et al. [2013], the wavelet coherency allows identification of scales and times when the time series are experiencing oscillations at a similar frequency, i.e., both the time series are in effect coupled. Thus, the Figure 10 presents a complete lack of coherence between GPS-TEC and IRI-TEC model at PAL and SJC to lower periods between 2 and 32 days, similar to that observed in Figures 8 and 9. Figure 10 also presents a phase difference of $45^{\circ}$ and $135^{\circ}$ inside narrow range periods 96 to 132 days between April and September (days 90 to 270) at PAL. However, vertical arrows are observed at SJC, 

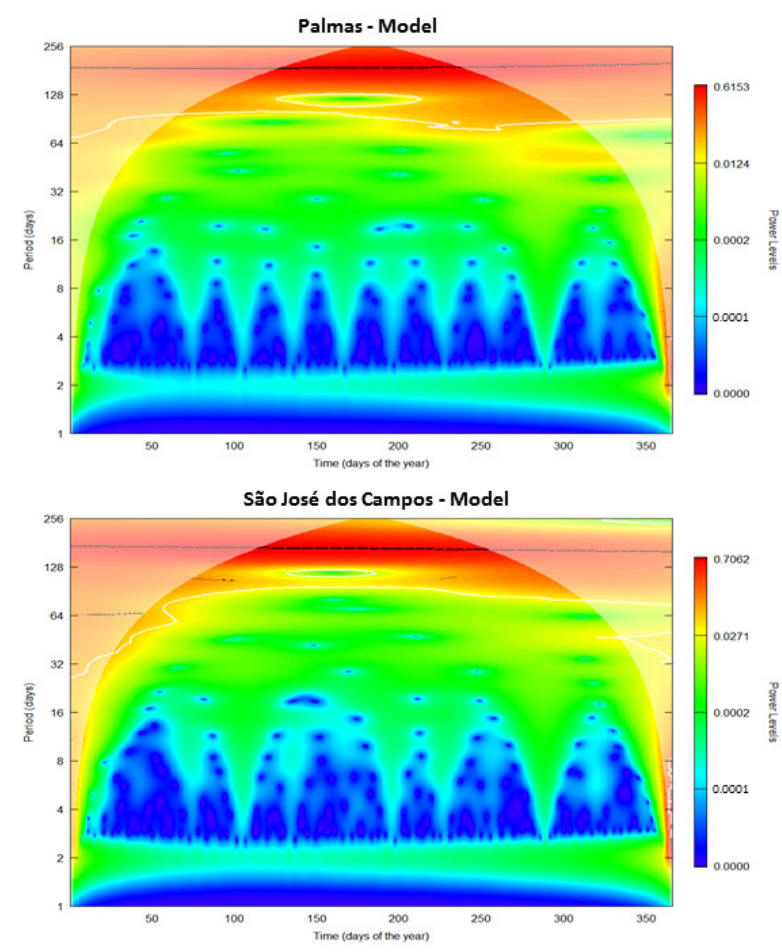

Figure 9. Continuous wavelet transform (CWT) power spectra analysis distribution of 2009 daily average TEC-model at PAL (top) and SJC (bottom). The vertical axis represents the daily period and the horizontal axis represents the day of the year.

with the same periods and months of PAL. Also, a phase difference of $220^{\circ}$ with periods of 128 days between April and June (days 90 to 160) are observed. Therefore, this study shows that, in the equatorial and low latitude regions during the solar minimum 2009, large discrepancies are observed between the GPS-TEC and IRI2012 model. Hence, further studies are needed to fully understand the discrepancies between experimental and modeled TEC values. This will include months of high and low solar activity.

\section{Conclusions}

In this paper, we have analyzed and presented a comparative study of ionospheric parameter GPS-TEC with the TEC from IRI-2012 model at PAL and SJC stations, nearly equatorial and EIA regions in the Brazilian sector, respectively. In order to understand the causes for the discrepancies between TEC measurements and the IRI-model prediction, this study focused on the deep low solar activity period of 2009 during the unusual solar cycle 23 . The wavelet analysis was used in the present study to identify the periodicities and coherence between experimental and modeled TEC values. The main results of this study are as follows:

1. The IRI-TEC model showed better agreement with the GPS-TEC during nighttime from January to
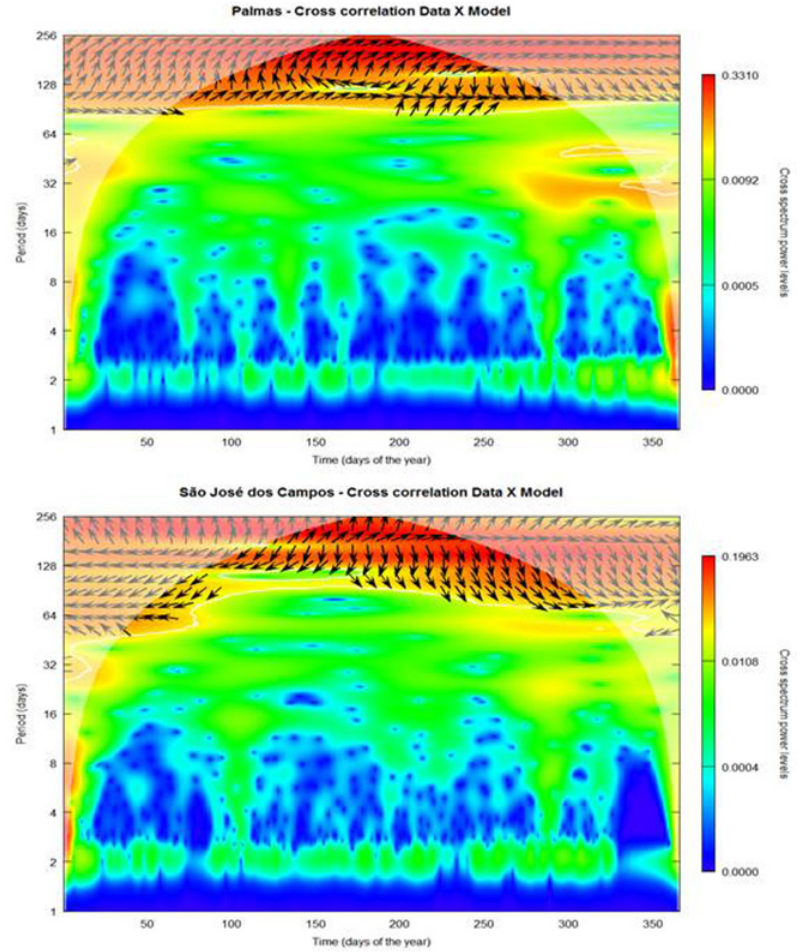

Figure 10. Wavelet coherence between daily average variations of GPS-TEC and TEC-model from PAL (top) and SJC (bottom) from January to December 2009. Arrows indicate the phase difference between GPS-TEC and TEC-model from PAL and SJC of the wavelet spectra (right arrows indicate series are in phase, left arrows indicate series are completely out of phase (180o), and an arrow pointing vertically upward means the second series lags the first by $90^{\circ}$.

December 2009 at PAL and SJC. The IRI-TEC model showed larger differences from the GPS-TEC in the afternoon hours, mainly at SJC. These discrepancies observed at SJC in the afternoon hours for all months are possibly due to the dynamics of EIA region in consequence of the equatorial fountain effect, which the IRI model fails to predict correctly.

2. At PAL and SJC, the GPS-TEC shows oscillations with periods around 16 days in April and periods around 27-32 days between September and December. Also, oscillations with periods around 2-4 and 5-10 days from January to December were observed at PAL and SJC. The largest oscillations possibly are related to the modulation of semidiurnal tide and Sun's rotation, respectively. The smallest oscillations possibly are associated with propagation of planetary waves. On the other hand, the IRI-TEC model oscillations showed total discrepancy with those seen from the GPS-TEC.

3. The wavelet coherence between the daily average variations of GPS-TEC and IRI-TEC model at PAL and SJC showed a complete lack of coherence to periods between 2 and 32 days. Therefore, this study showed large discrepancies between the GPS- 
TEC and IRI-2012 TEC model in the equatorial and low latitude regions during the solar minimum 2009 and more studies are needed to fully understand it.

Acknowledgements. Thanks are due to the Brazilian funding agencies for the partial financial support through grants 402685/20156 (CNPq) and 088861/2013 (PVS-CAPES-ITA). The authors thank the authorities of the "Rede Brasileira de Monitoramento Contínuo de GPS (RBMC)", Brazil and "Universidade do Vale do Paraíba (UNIVAP)", Brazil for easy access to their data. M.J.A. Bolzan thanks to CNPq through grants 302330/2015-1 and FAPEG through grants 2012-10267000905. Authors wish to acknowledge the GSFC, NASA for the online version of the IRI-2012 model (http:/ / omniweb.gsfc. nasa.gov/vitmo/iri2012_vitmo.html). One of the authors, Venkatesh wishes to express his sincere thanks to the "Fundação de Amparo à Pesquisa do Estado de São Paulo (FAPESP)", São Paulo, Brazil for providing financial support through the process No.2012/08445-9 and 2013/17380-0. R. de Jesus wish to express his sincere thanks to the Brazilian funding agency CNPq (project number 401634/2014-0; process number 150437/2015-3) for the partial financial support.

\section{References}

Abdu, M. A. Outstanding problems in the equatorial ionosphere-thermosphere electrodynamics relevant to spread F. J. Atmospheric and Solar-Terrestrial Physics, n. 63, p. 869-884, 2000.

Abdu, M. A. Equatorial ionosphere-thermosphere system: Electrodynamics and irregularities. Advances in Space Research, n. 35, p. 771-787, 2005.

Akala, A. O., Seemala, G. K., Doherty, P. H., Valladares, C. E., Carrano, C. S., Espinoza, J., and Oluyo, S., Comparison of equatorial GPS-TEC observations over an African station and an American station during the minimum and ascending phases of solar cycle 24, Annales Geophysicae, 31, 2085-2096, 2013.

Altadill, D., J.M. Torta, and E. Blanch, Proposal of new models of the bottom-side B0 and B1 parameters for IRI, Adv. Space Res., 43, 1825-1834, DOI: 10.1016/j. asr.2008.08.014, 2009

Bertoni, F., Sahai, Y., Lima, W.L.C., Fagundes, P.R., Pillat, V.G., Becker-Guedes, F., and Abalde, J.R., IRI-2001 model predictions compared with ionospheric data observed at Brazilian low latitude stations, Ann. Geophys., 24, 2191-2200, 2006.

Bhuyan, P. K., and R. K. Rashmi, TEC derived from GPS network in India and comparison with the IRI, Adv. Space Res., 39, 830-840, 2007.

Bilitza, D., International reference ionosphere: Recent developments, Radio Sci., 21, 343-346, 1986.

Bilitza, D. (Ed.), International Reference Ionosphere 1990, NSSDC Report 90-22, Greenbelt, Md., 1990.

Bilitza, D., International Reference Ionosphere 2000, Radio Sci., 36, 261 - 275, 2001.

Bilitza, D., and B. W. Reinisch, International Reference Ionosphere 2007: Improvements and new parameters,
Adv. Space Res., 42(4), 599 - 609, 2008.

Bilitza, D., D. Altadill, Y. Zhang, C. Mertens, V. Truhlik, P. Richards, L. A. McKinnell, and B. Reinisch, The International Reference Ionosphere 2012: A model of international collaboration, J. Space Weather Space Clim., 4, A07, 2014.

Bolaji, O. S., Adeniyi, J. O., Radicella, S. M., and Doherty, P. $\mathrm{H}$., Variability of total electron content over an equatorial West African station during low solar activity, Radio Science, 47, 2012.

Brunini, C., M. A. Van Zele, A. Meza, and M. Gende, Quiet and perturbed ionospheric representation according to the electron content from GPS signals, J. Geophys. Res. 108(A2), 1056, 2003.

Carey, S. K., Tetzlaff, D., Buttle, J., Laudon, H., McDonnell, J., McGuire, K., Seibert, J., Soulsby, C., Shanley, J. Use of color maps and wavelet coherence to discern seasonal and interannual climate influences on stream flow variability in northern catchments. Waterm Resources Research, v. 49, n. 1-14, doi: 10.1002/wrcr.20469, 2013.

Chakraborty, M., Kumar, S., Kumar de, B., and Guha, A., Latitudinal characteristics of GPS derived ionospheric TEC: a comparative study with IRI 2012 model, Annals of Geophysics, 57, 5, 2014.

de Abreu, A. J., Fagundes, P. R., Bolzan, M.J.A., Gende, M., Brunini, C., de Jesus, R., Pillat, V. G., Abalde, J.R., Lima, W.L.C. Traveling planetary wave ionospheric disturbances and their role in the generation of equatorial spread-F and GPS phase fluctuations during the last extreme low solar activity and comparison with High solar activity. Journal of Atmospheric and Solar-Terrestrial Physics, v. 117, p. 7-19, 2014a.

de Abreu, A.J., Fagundes, P.R., Gende, M., Bolaji, O.S., de Jesus, R., Brunini, C. Investigation of ionospheric response to two moderate geomagnetic storms using GPS-TEC measurements in the South American and African sectors during the ascending phase of solar cycle 24. Advances in Space Research, v. 53, p. 13131328, 2014b.

de Abreu, A.J., Fagundes, P.R., Bolzan, M.J.A., de Jesus, R., Pillat, V.G., Abalde, J.R., Lima, W.L.C. The role of the traveling planetary wave ionospheric disturbances on the equatorial $\mathrm{F}$ region post-sunset height rise during the last extreme low solar activity and comparison with high solar activity. Journal of Atmospheric and Solar-Terrestrial Physics, v. 113, p. 47-57, 2014c.

de Jesus, R., Sahai, Y., Guarnieri, F.L., Fagundes, P.R., de Abreu, A.J., Pillat, V.G., and Lima, W.L.C., F-region ionospheric parameters observed in the equatorial and low latitude regions during medium solar activity in the Brazilian sector and comparison with the IRI-2007 
model results, Advances in Space Research, 47, 718728, 2011.

Fagundes, P. R., L. P. Goncharenko, A. J. de Abreu, K. Venkatesh, M. Pezzopane, R. de Jesus, M. Gende, A. J. Coster, and V. G. Pillat, Ionospheric response to the 2009 sudden stratospheric warming over the equatorial, low, and middle latitudes in the South American sector, J. Geophys. Res. Space Physics, 120, 2015.

Goncharenko, L. P., A. J. Coster, J. L. Chau, and C. E. Valladares, Impact of sudden stratospheric warmings on equatorial ionization anomaly, J. Geophys. Res., 115, A00G07, 2010.

Goncharenko, L., J. L. Chau, P. Condor, A. Coster, and L. Benkevitch, Ionospheric effects of sudden stratospheric warming during moderate-to-high solar activity: Case study of January 2013, Geophys. Res. Lett., 40, 4982-4986, 2013.

Hady, A. A., Deep solar minimum and global climate changes, Journal of Advanced Research, 4, 209-214, 2013.

Jonah, O.F., de Paula, E.R., Muella, M.T.A.H., Dutra, S.L.G., Kherani, E.A., Negreti, P.M.S., and Otsuka, Y., TEC variation during high and low solar activities over South American sector, Journal of Atmospheric and Solar-Terrestrial Physics, 135, 22-35, 2015.

Kelley, M. C.; Makela, J. J.; Beaujardière, O. Convective Ionospheric Storms: A Major Space Weather Problem. Space Weather Quarterly, V. 4, n. S02C04, 2006.

Kenpankho, P., Watthanasangmechai, K., Supnithi, P., Tsugawa, T., and Maruyama, T., Comparison of GPS TEC measurements with IRI TEC prediction at the equatorial latitude station, Chumphon, Thailand, Earth Planets Space, 63, 365-370, 2011.

Kumar, S., Patel, K., and Singh, A. K., TEC variation over an Equatorial and Anomaly Crest region in India during 2012 and 2013, GPS Sol. 1-10, 2015a, 10.1007/ s10291-015-0470-4.

Kumar, S., Eng Leong Tan, and Sentanu Murti, D., Impacts of solar activity on performance of the IRI-2012 model predictions from low to mid latitudes, Earth, Planets and Space, 67:42, 2015b.

Kumar, S., Performance of IRI-2012 model during a deep solar minimum and a maximum year over global equatorial regions, J. Geophys. Res. Space Physics, 121, 2016.

Kutiev, I., Y. Otsuka, D. Pancheva, and R. Heelis, Response of low-latitude ionosphere to medium-term changes of solar and geomagnetic activity, J. Geophys. Res., 117, A08330, 2012.

Maltseva, O. A., Zhbankov, G. A., and Mozhaeva, N. S., Advantages of the new model of IRI (IRI-Plas) to si- mulate the ionospheric electron density: case of the European area, Advances in Radio Science, 11, 307311, 2013.

Mannucci, A.J., Wilson, B.D., Yuan, D.N., Ho, C.M., Lindqwister, U.J., Runge, T.F. A global mapping technique for GPS derived ionospheric total electron content measurements. Radio Sci. 33, 565-582, 1998.

Oron, S., D’ujanga, F. M., and Ssenyonga, T. J., Ionospheric TEC variations during the ascending solar activity phase at an equatorial station, Uganda, Indian Journal of Radio \& Space Physics, v. 42, pp. 7-17, February 2013.

Pancheva, D., Mitchell, N., Clark, R., Drobjeva, J., and Lastovicka, J: Variability in the maximum height of the ionospheric F2-layer over Millstone Hill (September 1998-March 2000); influence from below and above, Ann. Geophys., 20, 1807-1819, 2002.

Rawer, K., D. Bilitza, and S. Ramakrishnan, International Reference Ionosphere 78, Special Report, International Union of Radio Science (URSI), Brussels, Belgium, 1978.

Seemala, G. K., and C. E. Valladeres, Statistics of total electron content depletions observed over the South American continent for the year 2008, Radio Sci., 46, RS5019, 2011.

Takahashi, H., Lima, L.M., Wrasse, C.M., Abdu, M.A., Batista, I.S., Gobbi, D., Buriti, R.A., and Batista, P.P., Evidence on 2-4 day oscillations of the equatorial ionosphere h'F and mesospheric airglow emissions, Geophys. Res. Lett., 32, L12102, 2005.

Truhlik, V., D. Bilitza, and L. Triskova, Latitudinal variation of the topside electron temperature at different levels of solar activity, Adv. Space Res., 44 (6), 693-700, DOI: 10.1016/j.asr.2009.04.029, 2009.

Torrence, C., and Compo, G.P.A., Practical guide to wavelet analysis. Bull. Am. Meteorol. Soc. 79 (1), 61-78, 1998.

Tsai, H-F., Liu, J-Y., Tsai, W-H., and Liu, C-H., Seasonal variations of the ionospheric total electron content in Asian equatorial anomaly regions, Journal of Geophysical Research, v. 106, No. A12, p. 30,363-30,369, 2001.

Venkatesh, K., P. V. S. Rama Rao, P. L. Saranya, D. S. V. V. D. Prasad, and K. Niranjan, Vertical electron density and topside effective scale height (HT) variations over the Indian equatorial and low latitude stations, Ann. Geophys., 29, 1861 - 1872, 2011.

Venkatesh, K., P. R. Fagundes, G. K. Seemala, R. de Jesus, A. J. de Abreu, and V. G. Pillat, On the performance of the IRI-2012 and NeQuick2 models during the increasing phase of the unusual 24th solar cycle in the Brazilian equatorial and low-latitude sectors, J. Geophys. Res. Space Physics, 119, 5087-5105, 2014a. 
Venkatesh, K., Fagundes, P.R., de Jesus, R., de Abreu, A.J., Pillat, V.G., and Sumod, S.G., Assessment of IRI-2012 profile parameters by comparison with the ones inferred using NeQuick2, ionosonde and FORMOSAT-1 data during the high solar activity over Brazilian equatorial and low latitude sector, Journal of Atmospheric and Solar-Terrestrial Physics, 121, 10-23, $2014 \mathrm{~b}$.

Wanninger, L., Effects of the Equatorial Ionosphere on GPS, GPS World, p. 48-54, 1993.

Wu, Chin-Chun, Liou, K., Shan, Shao-Ju, and Tseng, C. L.: Variation of Ionospheric Total Electron Content in Taiwan Region of the Equatorial Anomaly from 19942003, Adv. Space Res., 41, 611-616, 2008.

${ }^{\star}$ Corresponding author: Alessandro J. de Abreu Instituto Tecnológico de Aeronáutica (ITA), Divisão de Ciências Fundamentais, São José dos Campos, SP, Brazil.; email: abreu.alessandro@gmail.com

2017 by Istituto Nazionale di Geofisica e Vulcanologia.

All rights reserved 